INTRACELLULAR DISTRIBUTION QR

PENTOBARBITAL SODIUM IN RAT BRAIN

by

Carol Jean oen

$* * * *$

\begin{abstract}
A Dissertation Presented to
the Faculty of the Graduate School, University of Missouri,
\end{abstract}

In Partial Fulfiliment

of the Requirements for the Degree

Master of Arts

January, 1958

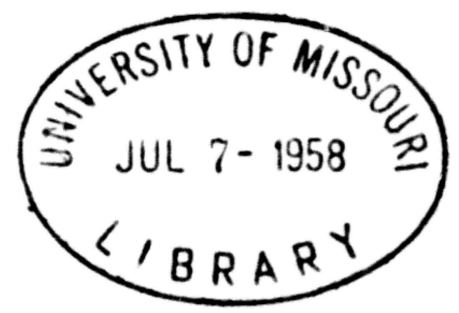


The undersigned, appointed by the Dean of the Graduate Faculty, have examined a thesis entitled

\section{INTRACELLULAR DISTRIBUTION OF}

\section{PENTOBARBITAL SODIUM IN RAT BRAIN}

presented by Carol Jean Oen

a candidate for the degree of Master of Arts

and hereby certify that in their opinion it is worthy of acceptance.

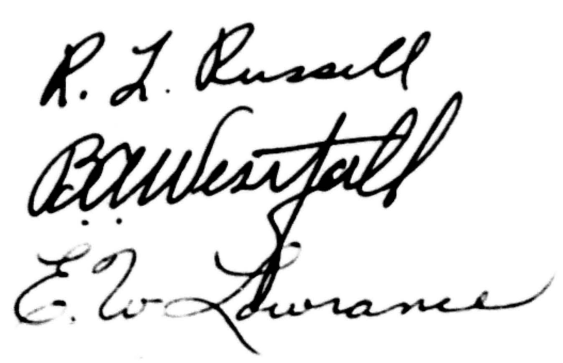


I. INTRODUCTION . . . . . . . . . . . I

II. LITERATURE REVIEW . . . . . . . . . 3

A. Barb1turates ........... 3

B. Barb1turate Analysis ......... 5

C. Cellular Fractionation ......... 7

III. METHODS ............... 9

A. Preliminary . . . . . . . . . . 9

B. Cellular Fractionation ........ 10

C. Barblturate Analys1s ......... 16

IV. RESULTS . . . . . . . . . . . 21

v. DISCUSSIONI . • . . . . . . . . . 27

vi. Conclusions . . . . . . . . . . . 33

VII. BIBLIOQGRAPHY . . . . . . . . . 34

VIII. ACKNOWLEDGEMEMT. . . . . . . . . . 42 


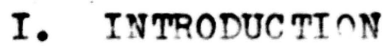

The mafor erfect of the barbiturates is depression of the central nervous system, but the way in which these

1

drugs exert their effect is not yet well understood. According to Goodman and G1lman (1955), there is evidence to Indicate that the barbiturater as a class act at all segmental lovels and at all lovels of functional organization of the central nervous system. Furthermore, the cerebral cortex and reticular activating system are most sensitive to barbiturate effects, the cerebellar, vestibular, and spinal systems less so, and the medullary system least sensitive.

A sublimation method of barbiturate analysis has been used to give evidence of a differential distribution or barblturates in the brain (E. Keeser and I. Keeser, 1927, 1935; E. Keeser and J. Keeser, 1927, 1929). Work by Koppany1, Dille, and Krop (1934) and by Koppany1 and D11le (1935) refutes the Keesers' work, as these workers round no difference in borbiturate concentration in the various divisions of the brain using elther the small doses (50-60 m1l11grams/k1logram) employed by the Keesers or large anesthet1zing doses (225-600 m1lligrams/k1logram). More recent work by Maynert and van Dyke (1950), using $\mathbf{N}^{15}$ labelled barbital also showed no localization of the drug in any particular division of the central nervous system. 
Schnelder and Hogeboom (1956) state that the fact that cells are seen to be exceedingly complex structures and not simply homogeneous masses of protoplasm $1 \mathrm{mpl}$ ies that this arrangement must have some functional signiricance. If all compounds and enzymes were uniformly distributed throughout the cell, there should be no resson for the existing discrete subcellular organization of the cell.

As the blochemicel functions of the cell and 1 ts various parts become bettor understood, 1t is of interest to relate the actions of arug to some particular runction (Reiner and Gelihorn, 1956). If 1 t were round that a barblturate were localized by a particular cellular component, this might mean that its effect was rendered through some function of that particular component. Consequently, this study was undertaken to determine the Intraceliular distribution of a particular barbiturate, pentobarbital sodium, within rat brain cells. 
II. LITERA TTIRE REVIEW

\section{A. Barbiturates}

The barbiturates may be classifled in three major ways; 1) structure, 2) length of action, and 3) site of detoxif1cation (Goodman and G1lman, 1955; Sollmann, 1957). Pentobarbital's structure 1 s that of the 5-ethyl-5(1-methylbutyl) derivative of barbituric ac1d; it is a short-acting berbiturate, and it is detoxifled mainly in the liver (Goodman and G11man. 1955).

Nutritional conditions such as starvation, anemia, or vitamin C deficiency may alter the slseping time under barbiturates (R1chards and Taylor, 1956). Kinsey (1940) showed that tolerance to pentobarbital develops rapidly in white rats, resulting in a marked reduction of sleeping time.

The concentration of barbiturate in the central nervous system parallels the depth of anesthesia, and the rato of penetration into the brain parallels the time of onset of effects (Butler, 1950). An equilibrium between the brain and the plasma levels of barbiturate is established quickly and remains relatively constant (Richards and Taylor, 1956). The concentration of barbiturates, other than thiopental, in the cerebrospinal fluid is usually very low (Goodman and G1lman, 1955). 
In clinical cases of barbiturate polsioning, the concentration of barbiturate in the brain is not very high (Sollmann, 1957). There as no close parallelism between clinical effect and the concentration of barbiturate in the blood (Helldorff, 1955).

In vitro studies using rabbit tissue homogenates ave shown that barbiturates are bound in the same order as In vivo, decreasing in amount bound from liver to kidney, to plasma, to brain, to red blood cells, to muscle (Goldboum and Sm1th, 1954). In the same etudy these invest1gators also established the fact that the pentobarbital penetrates the brain rapidiy and attains a higher concentration there than in the plasma.

Neurophysiological and electroencephalograph1c studies have established that the barbiturates elevate the threshold of neurons by stabilizing the cell membrane, and that they prolong the time for recovery from stimulation (Goodman and G1lman, 1955). Since there is an increase in the absolute and relative recovery times at cortical levels with increasing depth of pentobarbital anesthesis, wikler (1952) suggested that part of the effect of barbiturates is due to depressant effects in the thalamus. It is possible that a specific effect is exerted on the central mechanisms which regulate the sleep process (Goodman and G1lman, 1955). Even though variations of concentration in different parts 
of the brain have not been shown, a difference in sensitivity to a given level of drug may occur (Rlchards and Taylor, 1956).

The actions of pentobarbital on spinal cord and peripheral nerve ore essentially similar to 1 ts effects on the brain centers, except that higher doses are required to depress the spinal cord, and even greater doses are required to depress peripheral nerve (Goodman and G11man, 1955).

\section{B. Barb1turate Analys1s}

Earlier quant1tative analyses of barblturates were based upon gravimetric methods in which the barbiturate was extracted into an organic solvent, the solvent evaporated, and the residue purifled (Dybing, 1955). This sort of method has the disadvantages of requiring a great deal of time and a large amount of sample.

Colorimetric methods have been developed using colors produced by the reactions of barbiturates and varlous compounds of cobalt and copper, but application of these methods to blological material is not essy because of the low specificity and sensitivity (Raventós, 1954). spectrophotometry in ultraviolet light is now the preferred method. This type of analysis for the barbi- 
turates in general appearedest 1248 (G81dbaum, 1948; Walker, F1sher, and Mctugh, 1948). Earlier the same principle had been used for particular barblturates (Jaller and Goldbaum, 1946). Subsequently, the have been published several modifications and improvements of the spectrophotometric method (Dybing, 1955; Brodie, Burns, Mark, Lief, Bernstein, and Papper, 1953; Goldb̂um, 1952).

According to Walker, Fisher, and McHugh (1948), the limiting factor in the sensitivity of the spectrophotometric method is the ratio of barbiturates present to other interfering substances concomittantly extracted.

It is well known that berbiturates split in strongly alkaline solutions, but measurements cannot be made in acidic solutions because the absorption of ultraviolet light is too small (Dybing, 1955). Dybing (1955) studied the rate of splitting to determine if it were high enough to influence spectrophotometric determinations. At pH 10, the barbiturates were sufficlently stable to prevent splitting from influencing the determination, while $a$ wide range of stablity was found among the various barbiturates in 0.5 N. sodium hydroxide solution. Pentobarbital was not tested by this investigator.

It is claimed now thet Goldbaum's method of barb1turate analysis has an accuracy of about 95 per cent for concentrations of barbiturates as low as $1 \mathrm{~m} 1111 \mathrm{gram} / 100$ 
grams (or $10 \mathrm{micrograms/gram)} \mathrm{of} \mathrm{blood} \mathrm{or} \mathrm{t1ssue} \mathrm{(Goldbaum,}$ 1956).

\section{Cellular Fractionation}

Centrifugation has been used for isolation of particular cellular components for some time, but techniques for complete fractionation of cells by centrifugation have been used exterisively only since the later 1940's (De Duve and Berthet, 1954).

Fractionetion by mesns of centrifugation is besed on the fact that particles of different size or density sediment at different rates in a centrifugal force field. Conditions for centrifugation are chosen for esch fraction so as to cause complete sedimentation of the heavier particles with as little contamination as possible by the 11ghter ones (De Duve and Berthet, 1954). An approximate formula expressing the rate of sedimentation for a spherical particle in a centrifugal force fleld is

$$
\begin{aligned}
\frac{d x}{d t}=\frac{2 r^{2}\left(d_{p}-d_{m}\right)}{91} \omega^{2} x & \\
\text { where } x & =\text { distance traveled along the } \\
& \text { direction of the field in } \\
t & =\text { time In seconds } \\
r & =\text { radius of particle in centi- } \\
& \text { meters density of particle in grams/ } \\
d_{p} & \text { cubic centimeter } \\
d_{m} & =\text { density of suspension medium in } \\
& \text { grams/cubic centimeter }
\end{aligned}
$$




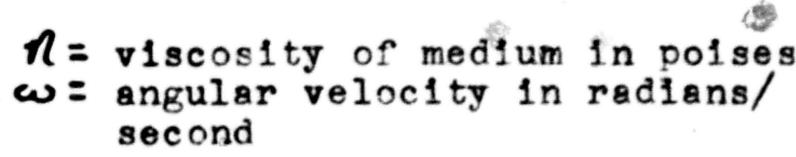

It is seen in the above formula that the governing factor in a given medium is represented by the term $r^{2}\left(d_{p}-a_{m}\right)$. Therefore, it is theoretically possible for smaller particles with higher density to have the same sedimentation rate as larger particles with a lower density. Not included in the above formula is the influencing factor of the particle's shape in sedimentation rates, but this is not appreciable unless there is pronounced asymmetry (De Duve and Berthet, 1954).

W1th high-speed centrifuges the total force applied is expressed os an integrel, the g-minute. Where the instrument is equipped with a "revolutions-per-minute" Indicator, a chart giving the value of the integral for different speeds can be devised essily. 
III. METHODS

\section{A. Prel1minery}

Adult, albino, maie rats were used throughout this study since it has been shown that the susceptibility of rats to barbiturates varies with age end sex (Mo1r, 1937).

It is recommended (De Duve and Berthet, 1954;

Schneider end Potter, 1949) that animals whose tissue is to be used for cell fractionetion be fasted previously for about 12 hours to reduce the glycogen content. Since the glycogen content of brain is very low (Dawson and Richter, 1950) and because brain glycogen differs from liver glycogen in that 1 t is not altered appreciably by starvation (West and Todd, 1955), the fasting period was eliminated.

Pentobarbital sodium wes chosen as the barbiturate for use in this investigation, since it is not stored in significant amounts by the body fat (Brodie, 1952). This eliminates error resulting fromdifferent percentages of body fat in the various animais.

The pentobaritel sodiun was prepared as a standard anesthetizing solution of 10 ililigrams of pentobarbital sodium per milliliter of normal ssilne solution. The dose used for anesthesia was 40 milligrams per k1logram of body weight (or $40 \mathrm{micrograms/gram),} \mathrm{given} \mathrm{intraperitoneally.}$ 
The time at which the animal could no longer support 1ts we1ght on 1 ts feet was taken to be the beginning of anesthesia. Exactly 20 minutes later the rat was decapitated, its brain removed as quickly as possible and chilled for a fow minutes in finely crushed 1ce (Brody and Bain, 1952). From this point until completion of the cellular fractionation procedure, all solutions, contalners, and the tissue itself were kept within a temperature range of $0-5$ degrees centigrade.

The chilled brain was blotted, then quickly and accurately weighed on a Roller-Sm1th precision balance.

\section{B. Cellular Fractionation}

The method employed for the separation of the cellular components was essentially that outlined by De Duve and Berthet (1954). The principle employed is differential centrifugation. A classification for that term was proposed by Anderson (1955), 1.e., fractions are collected consecutively at the bottom of the tube. The separation depends on differences in sedimentation rate. Centrifugations were carried out in an Intornet1onal Portable Refrigerated Centrifuge, Model PR-2, fitted with a high-speed, angle-head attachment. The temperature control was set at 0 to -2 degrees Centigrade in all instances. 
Ice-cold isotonic sucrose solution (.25 M.) was used as the homogenizing medium. No additional buffering agents were added since, in the words of De Duve and Berthet (1954),

"it
suitabie for the successful isolation
of one type of cellular component may
Influence unfavorably the separation
of another, and vice versa. At the
present time, salt-free solutions
would appear to be the best medium for
a complete fractionation."

The processes of homogenization and isolation of the nuclel were comblned as suggested by De Duve and Berthet (1954). Th1s was said to give more complete disruption of the cells with minimum damage to the components. The procedure was to add 1sotonic sucrose to the whole brain--the number of milliliters $=2.5$ times the brain weight. This mixture was then placed in a 40-mili111ter, glass, Ten-Broeck homogenizer surrounded by a container of ice water, and homogenized for a short time. This type of homogenizer is similar to that described by potter and Elvehfem (1936), the one recommended by De Duve and Berthet (1954) for use in this procedure.

The mixture from this first homogenization was poured into a 25-mill111ter, Lucite centrifuge tube and centrifuged at 10,000 gravity-minutes. The supernatant was pipetted off, using a rubber-bulbed pipette with a 90- 
degree angle near the tip.

The 1solation of the nuclei was completed in two additional steps, each involving further homogenization and centrifugation. The total number of milliliters of sucrose added in the three steps was equal to 9 times the brain weight. The milliliters of sucrose solution to be added in each of these two additional steps was calculated as follows: $\frac{1}{2} \mathbb{L}^{-}(9 \times$ brain we1ght $)-(2.5 \times$ brain weight $)-7=$ volume of sucrose solution in milliliters. After the addition of this amount of 1sotonic sucrose solution to the sediment from the first centrifugation, the mixture was transferred to the Ten-Broeck homogenizer and homogenized aga in for a short time, then centrifuged at 6,000 gravityminutes. The supernatant was again pipetted off and added to the supernatant from the first centrifugation. The final portion of 1sotonic sucrose solution was added to the sediment and the homogenization and centrifugation repeated as described above.

The combined supernatants were then ready for further fractionation. Mitochondria were the maln constituent of the sediment which was centrifuged down from the supernatants at 160,000 gravity-minutes. The supernatant from this was pipetted of as before. The sediment was washed by resuspending it in a volume of 1sotonic sucrose equal to the brain weight, followed by centrifugation 
at 130,000 gravity-minutes. Resuspension was accomplished by using a "micro-homogenizer", the rounded end of a FolinFu tube, which fits directly into a centrifuge tube, thus eliminating transfor of the solution for mixing. A second wash of the mitochondrial sediment was performed in the same manner. The supernatants from each wash were combined with that from the first centrifugation of the mitochonciria-containing solution.

Three basic fractions were thus obtained, "nucle1", mitochondria, and the finai supernatent. The "nuclear" fraction consisted of two fairly distinct layers; dense, fatty bottom layer fitting Brody and Bain's (1952) description of a gel-like residue, and hereafter referred to as "cellular debris", and a less dense, gray1sh, upper layer fitting De Duve and Berthet's (1954) description of the nuclear layer. These could be separated quite eas1ly by carefully plpetting off the upper layer. These four final fractions were then woighed accurately on the RollerSmith precision balance. Welghing was done directly in the tared centrifuge tubes by using a wire basket especially made to hold these tubes.

The weights of the various fractions were found to total considerably more than the original whole brain weight. Each retains some of the sucrose solution. Also some material is lost in the fractionation process, since 
14

the total woights do not equal the weight of the brain plus the weight of the sucrose added.

Some criterion was needed to compare the relative efficiencies of the various fractionations. It was decided that the welght of each rinal fraction expressed as a percentage of the original whole brain weight would give a simple measurement for this comparison.

The fractions were transferred to glass-stoppered bottles, using 2 milliliters of 1sotonic sucrose solution to a1d in the transfor. These were then stored in a refrigerator at 1 degree Centigrade unt1l time for analysis.

Microscoplc examination of the various fractions obtalned was made in 4 trial runs. As the particles were so dense, 1 drop of sedimented fraction was diluted with 2 drops of sucrose solution for easier examination. The cellular debris consisted of some apparently unbroken cells, many red blood cells, some particulate matter, and great deal of felly-like material forming matrix.

The nuclear fraction was found to be falrly uniform in larger particles, but some smalier particles were also evident.

The mitochondrial fraction contained falrly wide range of particle sizes. Attempts were made to differen- 
tiate the true mitochondrie from other material present in this fraction. A mixture or acetic acid and alcohol is known to dissolve mitochondria. One drop of mixture of acetic acid and absolute alcohol in 1:1 ratio was added to 1 drop of mitochondrial sediment on slide. Only larger particles could be seen. When 1 drop of sucrose was added to 1 drop of sediment, the large particles were visible, but there was high concentration of the smaller ones 180 .

The procedure for staining mitochondria with Janus Green B given by Guyer (1950) was tried. Janus Green B was made up in mammalian Ringer's solution in allution of 1:20,000. One drop of mitochondrial sediment was added to one drop of this solution on slide, a cover glass was applied, and the slide was examined. No staining was detected.

The Janus Green B was then made up in 1:5,000, $1: 10,000,1: 15,000$ and $1: 20,000$ in mammal1an Ringer's solut1on. These varlous dilutions wore tried on hemolyzed human blood, but again no staining was found to occur. The same dilutions of dye in normal saline instead of Ringer's solution gave an even medium-blue stain to spherical particles in the blood proparation. The stain in saline was then tried on the mitochondrial fractions. Some staining could be obtained only with the 1:5,000 dilution, and then only when 1 drop of sediment was added to 3 drops 
of dye solution. According to Cowdry (1918) Janus Groen B is specific for mitochondria only in very dilute solutions.

The supernetant fraction was found to be almost devold of particulate matter, and even though not diluted for microscopic examination, it must be remembered that this fraction is greatly diluted with the homogenizing medium. In this work the microsomes would also be expected to be present in the supernatant, though they are not easily differentlated microscopically.

A group of trials was made also on unanesthotized animals to serve as controls for the experimental determinat1ons. The same procedures were followed throughout, with the excoption of anesthetizing the enimals.

\section{Barbiturate Analrsis}

The spectrophotometric method of Goldbaum (1952) was used to determine the concentration of pentobarbital in the varlous samples. In this procedure the concentration 1s a function of the difference in optical density between barbl turate in sodium hydroxide and barbiturate in alkal1 buffered to $\mathrm{pH}$ 10.5. Pentobarbital in 0.9 N. sodium hydroxide exh1bits an absorption peak at 255 millimicrons. In pH 10.5 buffered solution, its peak is at 240 mill1m1crons (Goldbaum, 1952). 
In proliminary work unextracted standerd solutions wore compared with extracted ones. The same absorption peaks wore found, but the numerical values were considerably different. It was decided that extracted standerds would give a better comparison with extracted tissue values, so all were carried through the extraction procedure in experimental work.

The absorption spectrum of a solution of commercial pentobarbital sodium was compared with a solution of pentobarbital sodium made from the free acld in the manner described by Brodle, Burns, Mark, Llef, Bernstein, and Papper (1953). For purposes of comparison, the amount of sodium pentobarbital used was 1.097 times the amount of pentobarbital acid called for in the above paper. The curves obtained were, for all practical purposes, identical. Therefore, the commercial product was used for all standards as well as the anesthetizing solution. Ethylene dichloride (1,2-dichloroethane) was used to extract the barblturate from the practions, from a known standard in sucrose solution, and from sucrose solution alone. The ethylene dichloride needed for one set of extractions (about 400 milliliters) was washed in a separatory funnel with approximately 1.0 N. sodlum hydroxide solution using 1 milliliter sodium hydroxide to 10 mill1liters ethylene dichloride. Th1s inftial wash was 
followed by two washings with redistilled water, using the same volume ratio as for the sodium hydroxide.

A known standard of pentobarbital sodium in sucrose solution was made, using 100 micrograms of barbiturate per milliliter of 1sotonic sucrose. As each fractionation was run, 1 milliliter of this standard was diluted with 1 mill1liter of isotonic sucrose for use as working standard to be analyzed along with the varlous rractions of that run. This working standard was stored in the same type glassstoppered bottle as the fractions and for the same length of time.

Two milliliters of isotonic sucrose solution were used as a "blank" solvtion to be extracted and analyzed with each set of standard barbiturate and cellular rractions.

Thirty milliliters of ethylene dichloride were used to extract each blank and standard, 50 milliliters for each of the three sedimented rractions, and 100 milliliters for the supernatant rraction. These mixtures in 125-m111111ter separatory funnels were shaken 70 times per minute for three minutes on an Eberbach mechanical shaker. Then the ethylene dichloride (lower) layer in each separatory runnel was passed through whatman Number 41 filter paper into a second 125-m1lliliter separatory funnel.

Next, 4 milisilters of 0.0 N. sodium hydroxide were 
added to each sample. The normality of cthe sodlum hydroxIde had been prevlously adjusted such that, when diluted with a borate buffer ( $1 \mathrm{M}$. each--boric acid and potassium chloride) in equal volumes, the pH would be 10.5 as measured on a Beckman Model $\mathrm{G}$ pH meter. The borate buffer was made according to the directions given by Goldbaum (1952). The concentration of the buffer was found to change with time, so the adjustment of the sodium hydroxide normality was made each time an analysis was to be performed. Also, a fresh buffor solution was made at least every two woeks.

The sodium hydroxide-ethylene dichloride mixture was shaken for three minutes as bofore. Askevold and Ifoken (1956) found that shaking beyond 3 minutes during reextraction did not increase the recovery of barbiturate. The ethylene dichloride (lower) layer was discarded and the sodium hydroxide layer was run into 15-m1ll1liter centr1fuge tubes. These were contrifuged at the maximum velocity (3030 revolutions per minuto) of a Clay-Adams Safety-head centrifuge for 5 minutes.

The upper layers from the solutions in the contriruge tubes were pipetted off, and 3 milliliters of each were trensferred to callbrated, 1-centimeter, silica cuvettes. The optical density readings were then taken on - Beckman Model DU Spectrophotometer with ultraviolot 
accessories. The wave length setting for all readings was: 260 m1llimicrons. The semples were then diluted $1: 1$ with borate buffer and the optical density readings were taken again. Dilution was accomplished by plpetting off 1.5 milliliters from each cuvotte and replacing 1t with 1.5 milliliters of borate buffer solution. The contents of each cuvette were stirred with individuel, small, clean, stirring rods to ensure thorough mixing. It was also found advantageous to allow the diluted contents to stand a for minutes before taking the final readings. These rinal optical density readings were multiplied by 2 to correct for dilution of the barblturate.

After completion of the analytical procedure, the sil1ce cuvettes were placed in an approximately $3 \mathrm{~N}$. hydrochloric acid bath for about 1 hour, then rinsed several times in distilled water as suggested by Brodie, Burns, Mark, Llef, Bernstein, and Papper (1953) to minimize the reagent blank. 
The formula given by Goldbaum (1952) was used to determine the concentration of barbiturate in the various fractions.

M1crograms barblturate/gram of sample $=\frac{a b x c x d}{-x y g}$ where

$a=$ difference of unknown extract in alkal1 and in pH 10.5 at 260 millimicrons
$b=$ volume of ethylene dichloride used to extract samplo
$c=$ volume of alkali used to extract ethylene dichloride al1quot

$d=$ micrograms of barbiturate per milliliter of known alkaline extract

- = difference of known extract in alkall and in pH 10.5 at 260 millimicrons

$\mathbf{f}=$ othylene dichloride aliquot

$B=$ amount of sample

The results of the analysis of the control group of animals are shown in Table $I$. All practions exhiblt absorption at 260 millimicrons. In all cases, however, the absorption in the buffered solution was greater than that in the 0.9 N. sodium hydroxide, thus giving negative velues rather than the "ideal" condition of being zero in the absence of barbiturate.

The standard deviations found in the control group for the cellular debris, nucle1, mitochondria, and super- 
Table I

PENTOBARBITAL EQUIVALENT (MICROGRAMS/GRAM) CORRECTIONS FOR ISOLATED CELLULAR FRACTIONS FROM CONTROL ANTMALS

\begin{tabular}{|c|c|c|c|c|}
\hline $\begin{array}{r}\text { Tr1al } \\
\text { Number }\end{array}$ & $\begin{array}{c}\text { Cellular } \\
\text { Debris }\end{array}$ & Nucle1 & M1 tochondria & Supernatant \\
\hline $\mathbf{A}$ & $-1 \cdot 303$ & -1.460 & -5.035 & -.230 \\
\hline B & -1.114 & -1.453 & -4.003 & -.311 \\
\hline c & -1.552 & -1.200 & -3.202 & -.462 \\
\hline D & -2.016 & -0.977 & -4.4 .04 & -.282 \\
\hline $\mathbf{E}$ & -2.534 & -1.609 & -4.351 & -.306 \\
\hline $\mathbf{F}$ & -2.637 & -1.476 & -5.002 & -.22146 \\
\hline G & -1.863 & -1.211 & -3.535 & -.340 \\
\hline H & -1.962 & -1.015 & $-3.0,94$ & -.291 \\
\hline$I$ & -1.343 & -1.343 & -4.901 & -.198 \\
\hline$x$ & -1.814 & -1.305 & $-4 \cdot 270$ & -.296 \\
\hline$\sigma$ & .537 & . 218 & .649 & .076 \\
\hline S.E.M. & .190 & .077 & .229 & .027 \\
\hline
\end{tabular}


natant were $.537, .218, .649$, and .076 micrograms of pentobarbital per gram of fraction, respectively (Table I). The standard errors of the mean for these same fractions were found to be, respectively, .190, .077, .229, and .027 m1crograms of pentobarbital per gram of fraction (Table I).

In a rew experimental determinations the optical density difference was also found to be negative. A correction factor was applied to each experimental result. This factor was the average of the control group for that fraction as determined in Table $I$. This resulted in net positive reading in ell experimentel determinations which had prevlously been negative. These corrected values for the experimental group are given in Table II. The means and the standard orrors of means for the experimental group have been plotted in Figure 1. The standard deviations for the experimental groups of collular debris, nucle1, mitochondria, and supernatant were $6.037,9.022,4.36$, and 3.80 micrograms of pentobarbital per gram of fraction, respectively (Table II). The standard errors of the mean for these groups were found to be $1.67,2.50,1.26$, and 1.05 micrograms of pentobarbital per gram of fraction (Table II). It will be noted that the value for mitochondria was ommitted in trial number 5 (Table II). This was eliminated on the basis of Chauvenet's criterion for the rejection of suspected observations (Jarrett, 1949). 
Table II

CONCENTRATION OF PENTOBARBITAL SODIUM IN MICROGRAMS/GRAM OF ISOLATED CELLULAR FRACTION OF RAT BRAIN

\begin{tabular}{|c|c|c|c|c|}
\hline $\begin{array}{l}\text { Trial } \\
\text { Number }\end{array}$ & $\begin{array}{l}\text { Cellular } \\
\text { Dobris }\end{array}$ & Nucle1 & M1tochondria & Supernatant \\
\hline 1 & 11.43 & 13.32 & 5.93 & 16.73 \\
\hline 2 & 9.11 & 214.64 & 7.08 & 19.52 \\
\hline 3 & 13.39 & 10.67 & 3.73 & 14.05 \\
\hline 4 & 7.85 & 10.19 & 10.16 & 12.01 \\
\hline 5 & 17.40 & 16.35 & & 21.61 \\
\hline 6 & 9.06 & 36.15 & 3.58 & 21.93 \\
\hline 7 & 1.03 & .84 & 5.27 & 10.95 \\
\hline 8 & 16.23 & .98 & 9.91 & 11.38 \\
\hline 9 & 1.58 & 6.68 & 3.34 & 12.31 \\
\hline 10 & 1.48 & 12.26 & 10.47 & 13.38 \\
\hline 11 & 15.86 & 10.66 & 8.15 & 214.48 \\
\hline 12 & 11.11 & $24 \cdot 49$ & 28.88 & 20.02 \\
\hline 13 & 1.10 & $14 \cdot 10$ & 6.11 & $24 \cdot 43$ \\
\hline 14 & 15.13 & 18.25 & 7.89 & 14.18 \\
\hline$\overline{\bar{x}}$ & 9.41 & 13.54 & 8.50 & 15.50 \\
\hline$\sigma$ & 6.04 & 9.02 & $4 \cdot 36$ & 3.80 \\
\hline S.E.M. & 1.67 & 2.50 & 1.26 & 1.05 \\
\hline
\end{tabular}




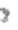

Figure 1

Cellular Debris

AIV Nucle1

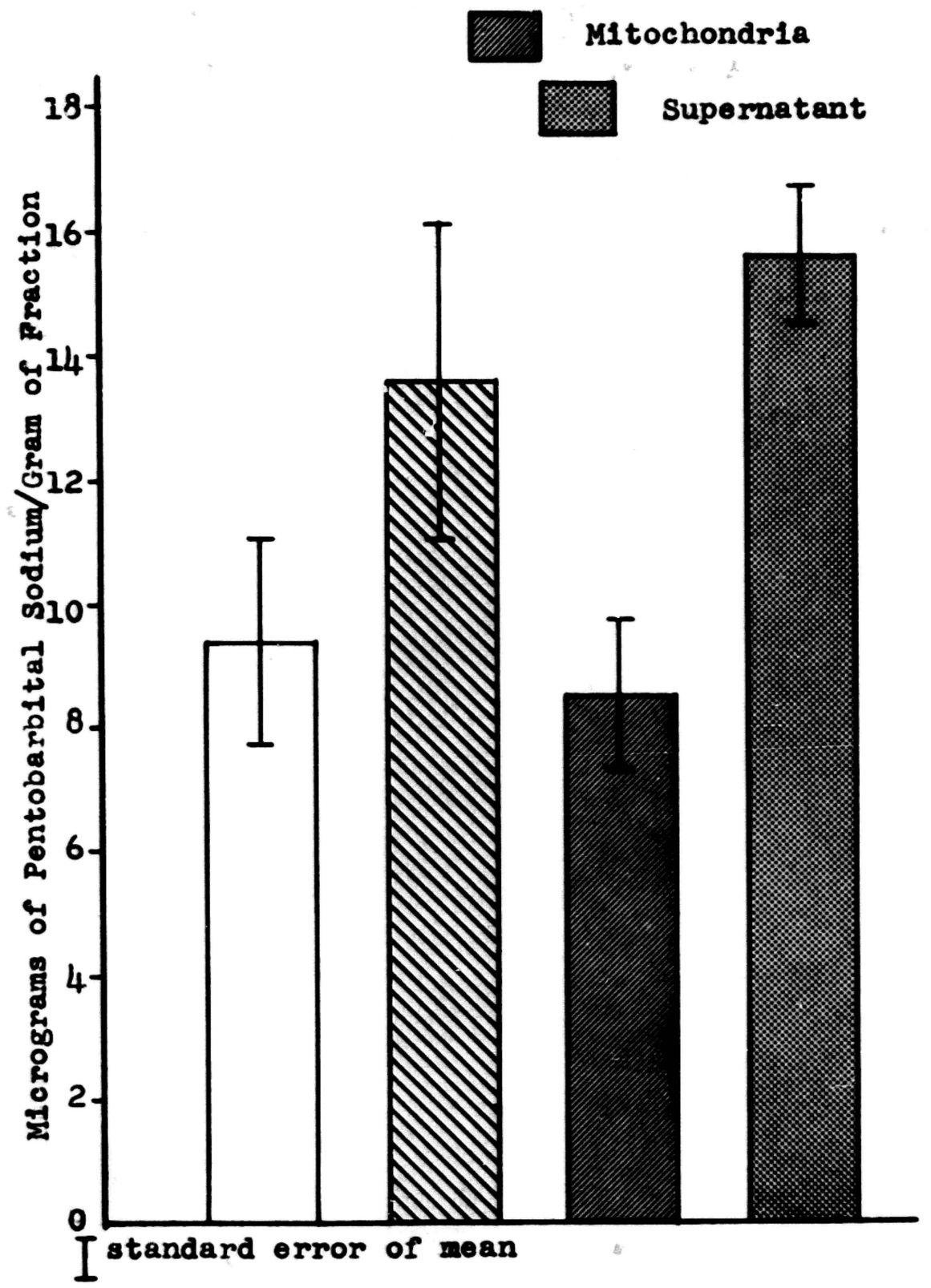

CONCENTRATION OP PENTOBARBITAL SODIUM IN MICROGRAMS/GRAM OF 
The "t" test was applied to the values for each possible pair of experimental fractions (MeNemar, 1949). The probability that the difference in value between each pair of fractions is due to chence was found from the "tn value on a table complled by Treolar (1951). The following Table III summerizes these tests for significance.

Table III

A COMPARISON OF PENTOBARBITAL SODIUM CONTENT IN THE CELLULAR FRACTIONS OF RAT BRAIN

\begin{tabular}{|c|c|c|c|c|c|}
\hline $\begin{array}{l}\text { Cellular } \\
\text { Debris }\end{array}$ & Nucle1 & M1 tochondria & Supernatant & $\mathbf{t}$ & $\mathbf{P}$ \\
\hline$x$ & $x$ & & & 1.093 & $>.281$ \\
\hline$x$ & & $x$ & & .375 & 7.68 \\
\hline$x$ & & & $\mathbf{X}$ & 3.20 & .004 \\
\hline & $\mathbf{x}$ & $X$ & & 1.65 & $>.102$ \\
\hline & $x$ & & $\mathrm{X}$ & .75 & $\geq .1+31$ \\
\hline & & $\mathrm{X}$ & $x$ & 3.42 & .002 \\
\hline
\end{tabular}

From Table III there is seen to be a statistically significant difference between the values for the concentration of barbiturate in the cellular debris versus the supernatant $(P=.004)$ and the mitochondria versus the supernatant $(P=.002)$. 


\section{v. DISCUȘSION}

Studies of subcellular structure and function are still in their Infancy (Schnelder and Hogeboom, 1956) and methods avallable are far from 1deal.

Anderson (1954, 1955, 1956) has done series of studies on isoleted cell components including the effects of pH, density, viscosity, and composition of suspending medium, as well as methods of preparing homogenates. Anderson (1955) also studied the effects of centrifugation artefacts and has devised a strobosconic 1llumination method for obtaining very accurate centrifuge speeds. In the work reported here, the efficiency of the separation of the cellular components is not great. Due to the very nature of the principle of differential centrifugation, however, a perfect separation would be impossible (De Duve and Berthet, 1954). The separation of fractions may also be influenced by the addition of arug in large quantities or addition of a substance having a very large molecular weight (Relner and Gellhorn, 1956), thus increasing the density of the particles to which it might be bound.

Aldridge (1957) compared liver and brain mitochondria from rats. This study showed that brain mitochondria were less stable than liver mitochondria. 


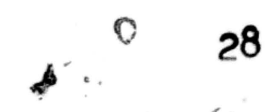

Aldridge (1957) states that it is very difficult to obtain a "pure" preparation or mitochondria from brain and attributes discrepancies in published information on brain mitochondria to this ract. According to Brody and Bain (1952), with studies on rats and rabbits, the sizes and shapes of the intraceliular particles vary to a much greater degree than they do in liver. From this fact it would be expected that the rractions would not be as uniform or "pure" as those obtained from 11ver.

All fractions retained some of the sucrose homogen1zing medium. It was not known whether or not this retention was proportional to the amount of sample. It might bo expected that mitochondria, for example, would retain much more since these particles are capable of expanding to many times their normal size (slekevitz, 1957). It has been shown by Jackson and Pace (1956), however, that the rate of diffusion of sucrose into mitochondria was considerably slower than diffusion of sucrose into a sphere of water of the same size. It was also shown by Jackson and Pace (1956) that sodium and potassium enter the mitochondria more repidly than sucrose. Entrance of all three of these substances occurs unt1l an equilibrium concentration is reached.

All tissues show some absorption at all wave lengths, thus making control values necessary for finding 
the true relationships between "blank" and barbituratecontaining tissue. Blank curves are especielly desirablo If the tissue to be examined contains a high percentage of fat (Goldbaum, 1956). Brain has a high lipid content--12 to 15 per cent in rresh adult human brain (West and Todd, 1955). It is interesting to note (Table I) that the blank values vary for the different fractions. Goldbaum (1956) found an optical density value of .12 at 255 mili1microns for "blank" rabbit brain tissue.

Chloroform is used as a solvent in barbiturate extractions from blood and from most tissues, but other or ethylene dichloride is preferable for brain because emulsions with interfering substances do not give as much trouble (Goldbaum, 1956).

Sulphonamides and salicylic acld are known to interfere with barbiturate determinations (Dybing, 1955), but neither of these occur normelly and would not be expected as a source of error in this study.

An apparent difference was found among all the cellular fractions isolated. The supernatant had the highest concentration of pentobarbital sodium and the mitochondria least, with cellular debris and nuclei second and third, respectively (Table II).

since the microsomal fraction was not isolated, these particles would be expected to appear in the super- 
natant.

Koppany 1, D1110, and Krop (1934) noted that the barbiturates were bound to lecithin in the brain, making. analysis by their mothod difficult. Assuming that ilpids do hold pentobarbital sodfum, it would be expected thet the cellular debris fractions would contain a high concentration of the drug since it seemed to be very fatty. If the barbiturate adheres to the cellular membrane where it seems to have an effect in decreasing permeability of the membrane (Sollman, 1957), then too, a higher concentration would be expected in the cellular debris eraction which would contain the cell membranes as well as some unbroken cells.

The effect of barbiturates is in uncoupling the oxidation-phosphorylation mechanism according to Brody and Bain (1951). Since the enzymes for oxidative phosphorylation are loceted primarily in the mitochondria (Schneider and Hogeboom, 1956), It might be expected that a high concentration of barbiturate be found in that rraction. There is a possibility that barbiturates may be bound to lipids. As lipids have a specific gravity less than $I$ (Kleiner, 1951) and consequently are less susceptible to sedimentation, they may occur in greatest concentration in the supernatant fractions. This then may be related to the fact that the concentration of pentobarbital 
is highest in the supernatant fraction. Also, bocause the supernatant fraction is probably diluted with the sucrose solution to a considerably greater degree than are any of the other fractions, the concentration of barbiturates in the ground substance of the cell, and in this case, the microsomes also, is actualiy greater than the values indicate.

Recent investigations on binding and distribution of other 1ons and substances using similar methods have appeared in the litereture. For example, Reiner and Gellhom (1956) studied the binding of quinacrine by liver cell constituents in tissue homogenates, by 1solated nuclei, mitochondria, and cytoplesm. It was found thet distribution among cell constitients was similar when the drug was administered in vivo and when added to homogenetes. From their results it was concluded that numerous cell const 1 tuents are capable of binding quinacrine and that no single chemical entity is responsible for the binding. Griswold and pace (1956) studied the intracelluler distribution of metal lons in liver tissue. Sodlum was found in greatest concentration in the supernatant, least in mitochondria, with microsomes and nuclei renking second and third. In studies of the intracellular distribution of catecholamines in the brain (We1l-Malherbe and Bone, 1957), adrenaline and hydroxytyramine were found in greatest concentration in the 
supernatant. Mitochondria were not greatly smaller in value, however, and were the highest in localization of noradrenaline.

Further work would seem desirable to relate the concentration of pentobarbital sodium in the cellular fractions to various depths of anesthesia. It would aiso be Interesting to investigate the intracellular distribution of the drug in the various anetomical divisions of the brain.

Work should also be done with thiopental, the sulfur analog of pentobarbital, to investigate its intracellular distribution at various time intervals. 
1. After 20 minutes of anesthesia at a dose of 40 micrograms of pentobarbital sodium per gram of body weight, this barbiturate was found in verying concentrations in the cellular debris, nucle1, m1tochondria, and supernatant fractions of rat brain cells.

2. There is a signiflcant difference $(P=.004)$ between the pentobarbital content of the supernatant fraction (mean $=15.50 \mathrm{~m} 1 \mathrm{crograms} / \mathrm{gram}$ ) and the content of the cellular debris fraction (mean $=0.41 \mathrm{micrograms} / \mathrm{gram}$ ).

3. There is significant difference $(P=.002)$ between the pentobarbital content of the supernatant fraction (mean $=15.50 \mathrm{micrograms} / \mathrm{gram}$ ) and the content of the m1 tochondrial fraction (mean $=8.50 \mathrm{~m} 1 \mathrm{crogrems} / \mathrm{gram}$ ).

4. There is no significant difference between the pentobarbital content of the cellular debris and the nuclear fraction $(P>.281)$, cellular debris and mitochondrial praction ( $P>68$ ), nuclear and mitochondrial fraction $(P>.102)$, and between the nuclear and supernatant fraction ( $P>.431$ ). 
Aldridge, W. N., 1957. Liver and Brain Mitochondria. Blochom1cal Journal, 67:423.

Anderson, N. G., 1954. Studies on Isoleted Cell Components. VII. A Reexamination of the Preparation and Properties of Rat Liver Homogenates. Experimental Cell Research, 8: $91-100$.

-..---., 1955. Studies an Isolated Cell Components. VITI. High Pesolution Gradient Differential Centrifugation. Experimental cell Research, 2:4/46-1459.

-...-.-., 1956. Studies on Isolated Cell Components. IX. The Soluble Phase. Experimental Cell Research, 11:186-196.

Askevold, R., and F. Loken, 1956. Quant1tative Determination of Barbital in Blood Serum by Oltraviolet Absorption Spectrophotometry. The Scandinavian Journal of Clinical \& Laboratory Investigation, $8: 1$.

Brodie, Bernard B., 1952. Physlological Disposition and Chemical Fate of Thlobarbiturates in the Body. Federation Proceedings 11, June, 1952.

Brodle, Bernard B., J. J. Burns, Lester C. Mark, Philip A. 
Lief, Eleonore Bernstein and E. M. Papper, 1953. The Fate of Pentobarbitál in Man and Dog and a Method for Its Estimation in Blological Material. Journal of Pharmaculogy and Experimental Therapeut1.cs, 109: 26-34.

Brody, Theodore M., and James A. Bain, 1951. Effect of Barbiturates on 0xidative Phosphorylation. ProceedIngs of the Soclety for Experimental Blology and Medicine, 77:50-53.

Brody, T. M., and J. A. Bain, 1952. A Mitochondr1al Preparat1on from Mammalian Bra1n. Journal of Blological Chemistry, 195:685-696.

Butler, T. C., 1950. The Rate of Penetrat1on of Barbituric Ac1d Derivatives Into the Brain. Journal of Pharmacology and Experimental Therapeutics, 100:219-226.

Cowdry, E. V., 1918. The Mitochondrial Constituents of Protoplasm. Carnegie Institution, Contributions to Embryology, 7-s:39-160.

Dawson, R. M. C., and D. Richter, 1950. Erfoct of Stimuletion on the Phosphate Esters of the Brain. American Journal of Phys1ology, 160:203.

De Duve, Chr., and J. Berthet, 1954. The Use of Different1al Centrifugation in the Study of T1ssue Enzymes. 
International Reviow of Cytology, III:225-275.

Dybing, F., 1955. Estimation of Barbiturates in Clinical Chemistry. The Scandinavian Journal of Clinical \& Laboratory Invest1gation, $I$ (Suppl. 20):114-123.

Goldbaum, L. R., 1948. An Ultrav1olet Spectrophotometr1c Procedure for Determination of Barbiturates. Journal of Pharmacology and Experimental Therapout1cs, 944:68.

Goldbaum, Loo R., 1952. Determinat1 on of Barb1turates. Analytical Chem1stry, 래:1604.

Goldbaum, Leo R., 1956. Barbiturates, Spectrophotometric Method of Goldbaum. Flde, Gradwohl, R. B. H., 1956. Clinical Laboratory Methods and D1agnosis, 22:2287-2289, 5th Edition, C. V. Mosby Company, St. Louls.

Goldbaum, Leo R., and Paul K. Sm1th, 1954. The Interaction of Barbiturates with Serum Albumin and Its Possible Rolation to Their Disposition and Pharmacological Actions. Journal of Pharmacology and Exporimental Therapeut1cs, 111:197.

Goodman, Louls S., and Alfred G1lman, 1955. The Pharmacological Basis of Therapoutics. Second Edition; 
The Macmillan Company, New York.

Griswold, R. L., and N. Pace, 1956. The Intracellular D1stribution of Metal Ions in Rat L1ver. Experimental Cell Research, 11:362-367.

Q.

Guyer, Michael F., 1950, An1mal Micrology. Fourth Rev1sed Edition; University of Chicago Press, Chicago, Illinols.

Helldorf, Ivar, 1955. On the Determination of Barbiturates. The Scandinavian Journal of Clinical \&aboratory Invest1gation, 7 (Suppl. 20):127-128.

Jackson, Kenneth L., and Nello Pace, 1956. Some Permesb1l1ty Properties of Isolated Rat Liver Cell Mitochondria. Journal of General Physiology, 40:47.

Ja1ler, Joseph W., and Loo R. Goldbaum, 1946. Studies on the Plasma Concentration and T1ssue Distribution of Sodium Pentothal. Journal of Laboratory and clinical Modicine, 31:1344-1349.

Jarrett, Alan A., 1946. Stat1st1cal Methods Used in the Measurement of Radioactivity (Some Useful Graphs). Technical Information Branch, Oak R1dge, Tennessee, AEC, Oak R1dge, Tennessee, 4-29-49--300-A9417. 
Keeser, E., and I. Keeser, 1927. Über den Nachweis von Morphin und Barbitursaurederiveten im Gehirn. Archiv fur Experimentelle Pathologie und Pharmakologie, 127:230-235.

Keeser, E., and J. Keeser, 1927. Über die Lokalisation des Veronals, der Phenyläthyl- und Diallylbarbitursaure Im Gehirn. Archiv für Experimentelle Pathologie und Pharmakologie, 125:251-256.

Keeser E., and J. Keeser, 1929. D1e Bedeutung der Sublimet1on Für die Erforschung Pharmakologischer Fragen. Archiv für Experimentelle Pathologie und Pharmakologie, 147:360-365.

Keeser, Ed., and Irmg. Keeser, 1935. Studies on Barbiturates, Distribution of Barbiturates in the Brain. Remarks on the Publication of the Same T1tle by Koppany 1, D111e and Krop. Journal of Pharmacology and Experimental Therapeutics, 53:137.

Kinsey, V. E., 1940. Use of Sodium Pentobarbital for Repeated Anesthesia in white Rat. Journal of the American Pharmacoutical Association (Scientific Edition), 29:387. 
Kleiner, Israel S., 1951. Human Blochemistry. Third Ed1tion; C. V. Mosby Company, St. Louls.

Koppany 1, Theodore, and James M. D11le, 1935. Remarks on the Distribution of Barbiturates in the Brain. Journal of Pharmacology and Experimental Therapeutics, $54: 84$.

Koppany 1, Theodore, James M. D11le, and Stephen Krop, 1934. Studies on Barbiturates. VIII. Distribution of Barbiturates in the Brain. Journal of Pharmacology and Experimental Therapeutics, 52:121.

Mc Nemer, Quinn, 1949. Psychologicel Statistics. John Wiley and Sons, Inc., New York.

Maynert, E. W., and H.B. van Dyke, 1950. The Abserice of Localization of Barbital in Divisions of the Centrel Nervous System. Journal of Pharmacolog: and Experimental Therapeutics, $28: 184$.

Mo1r, W. N., 1937. Influence of Age end Sex on Repeated Administration of Sodium Pentobarbital to Albino Rats. Journal of Pharmacology and Experimental Therapeutics, 59:68-85. 
Potter, V. R., and C. A. Elvehjem, 1936. A Modifled

Method for the Study of Tissue ox1detions.

Journal of Blological Chemistry, 114:495.

Ravent6s, J., 1954. The D1stribution in the Body and Metebolic Fate of Barbiturates. Journal of Pharmacy and Pharmacology, $\underline{6}: 217-235$.

Reiner, L, and Alfred Gellhorn, 1956. Localization of Drugs Within Cells. Binding of Quinacrine by Liver Cell Constituents. Journal or Pharmacology and Experimentel Therapeutics, 117:52.

Richards, R. K., and J. D. Taylor, 1956. Some Factors InPluencing Distribution, Metabolism and Action of Barb1turates: A Reviow. Anestheslology, 17:3.

Schne1der, Walter C., and George H. Hogeboom, 1956. B10chemistry of Cellular Particles. Annual Revier of Blochem1stry, 25:201-224.

Schnolder, Walter C., and Van R. Potter, 1049. Intracellular Distribution of Enzymes. IV. The Distribition of oxalacet1c 0xidase Activity in Rat Liver and Rat K1dney Fractions. Journal of Blological Chemistry, 177: 893-903. 
41

Slekevitz, Philip, 1957. Powerhouse of the Cell. Sclentif1c American, 197:131-140.

Sollmann, Torald, 1957. A Manual of Pharmacology. Elghth Edition; W. B. Saunders Company, Philadelphia, Pennsylvania.

Treolar, Alan E., 1951. Blometric Anelys1s, An Introduction. Burgess Publishing Company, Minneapolis, Minnesota.

Walker, J. T., R. S. Fisher, and J. J. MeKugh, 1948. Quantitative Estimation of Barbiturates in Blood by Ultraviolet Spectrophotometry. I. Analyt1cal Method. Americal Journal of Clinical Pathology, $18: 451$.

Well-Malherbe, $\mathrm{H}_{\bullet}$, and A. D. Bone, 1957. Intracellular Distribution of Catecholamines in the Brain. Nature, $180: 1050$.

West, Edward Staunton, and W1lbert R. Todd, 1955. Textbook of Blochemistry. Second Edition; The Macmillan Company, New York.

Wikler, A., 1952. Relationships Between Clinical Effects of Barbiturates and Their Neurophysiological Mechanisms of Action. Federation Proceedings, $\underline{11}: 647$. 


\section{ACKNOWLEDG EMENT}

Appreciation is expressed to Dr. R. L. Russell, under whose direction this study was made, for h1s advice, assistance, and encouragement; to Dr. B. A. Westrall and Dr. D. K. Meyer for thelr many timely suggestions; to the Nat1onal Sclence Foundation for a predoctoral fellowship during the 1956-57 academic year; to the Department of Physlology and Pharmacology for graduate assistantehip during the fall semester of 1957; and to all the members of the Department of Physiology and Pharmacology for their cooperation and many kindnesses. 
University Libraries

University of Missouri

Digitization Information for Theses and Dissertations project. Scanned from microfilm; no subsequent editing done.

Local identifier

Source information

Identifier

Format

Content type

Notes

Capture information

Date captured

Scanner manufacturer/model ScanPro 3000 /e-ImageData

Scanning software

Optical resolution

Compression

Color settings

File types

Notes

Derivatives - Access copy
Microfilm reel\# T1958-59-T1958-70

Microfilm

Text

2019

PowerScan $3000(\mathrm{TM})$ V5.341

$600 \mathrm{dpi}$

LZW

bitonal

tiff

Scanned from microfilm; no editing done.
Editing software

Resolution

Color

File types

Notes
Photoshop

600 dpi

grayscale

pdf

Converted from tiff to pdf using Adobe Acrobat Pro DC. 